\title{
EDUCAÇÃO EM AMBULATÓRIO DE PEDIATRIA
}

\author{
Education in the pediatrics clinic \\ Educación en el ambulatorio de pediatría
}

\section{Apresentação}

Fernando Ramos Porto ${ }^{1}$

0 artigo intitulado "Educação em ambulatório de Pediatria", da autoria de Maria do Carmo Marcondes Machado, registra a problemática da assistência à criança brasileira, especificamente no estado de São Paulo, e o investimento das enfermeiras responsáveis pelo Ambulatório de Pediatria do Hospital das Clínicas para proporcionar melhores condições de saúde àquelas crianças. A autora evidencia o baixo nível econômico em função da miséria em que vivia a população e o baixo nível espiritual, compreendendo os aspectos relacionados à instrução, mental e moral. Ainda a respeito desse último nível, a autora afirma a existência de correlação direta ao nível econômico, pela impor tância atribuída à instrução das mulheres que cuidavam de seus filhos.

Ademais, Maria do Carmo Marcondes Machado exemplifica, por meio de situações vivenciadas no Ambulatório de Pediatria, excertos sobre a realidade das condições socioeconômicas da população. Destaca que, diante do baixo nível econômico, o apego e o devotamento das mães pelos seus filhos não eram atingidos, e os casos de maus cuidados às crianças eram devidos à miséria e à baixa instrução.

Com a finalidade de oferecer melhores condições para os cuidados às crianças, as enfermeiras do Ambulatório de Pediatria criaram um grupo de mães intitulado "Club de Mães". Neste "club", elas orientavam as mulheres por meio de preleções e filmes educativos como estratégia de aproximação para administração de vacina às crianças, com resultados antes não atingidos, apesar, ainda, da baixa adesão dos pais ou responsáveis.

Ressalta, porém, que aquela atividade estava em desenvolvimento há meses e melhor seria se os casos do ambulatório fossem seguidos de visitas domiciliares. Para tanto, fez-se necessária uma articulação com a Escola de Enfermagem de São Paulo, pois, assim, os casos agudos e outros poderiam ser atendidos pelas alunas daquela Escola como "serviço domiciliário de urgência".

Estratégias para a melhoria da qualidade de vida das crianças brasileiras, como a que a autora do artigo nos relata, são desafiadoras para as instituições de saúde até os dias atuais, no sentido da articulação com as escolas/cursos de Enfermagem no âmbito do ensino, pesquisa e extensão.

\footnotetext{
1 Doutor em Enfermagem. Professor Adjunto do Departamento de Enfermagem Materno-Infantil da Escola de Enfermagem Alfredo Pinto, membro fundador do NUPHEBRAS da Escola de Enfermagem Anna Nery/UFRJ e do LAPHE da Escola de Enfermagem Alfredo Pinto/UNIRIO, e pós doutorando da Escola de Enfermagem da Universidade de São Paulo no grupo de pesquisa Legislação e História da Enfermagem.
} 


\section{Presentation}

Fernando Ramos Porto ${ }^{1}$

The article entitled "Education in the Pediatrics Clinic", written by Maria do Carmo Marcondes Machado, analyzes the difficulties that exist in relation to the care of children in Brazil - specifically in the State of San Paulo, and emphasizes the efforts of the nurses responsible for the Pediatric Clinic of the Hospital of the Clinics aimed at improving the health conditions for these children.

The author highlights the low socio-economic level in which the population lives, that is the result of poverty and of a low spiritual level - including aspects related to mental and moral education. And, in relation to the moral education, the author acknowledges a direct relation to the economic level due to the significance attributed to the poor level of education of the women caring for their children.

On the other hand, Maria do Carmo Marcondes Machado exemplifies the situations lived in the Pediatrics Clinic, extracts from the reality of the socio-economic conditions of the population. She emphasizes that despite the low social economic level, the commitment and dedication of the mothers towards their children is not developed, and the cases of poor attention to the children are mainly caused by poverty and poor levels of education.

In order to provide better care for the children, the nurses of the Pediatric Clinic created a group for mothers called the "Moms' Club." In this "group", the nurses guide women using instructions, exercises and films with educational content. This is part of a strategy that aims to get more children vaccinated - with results never achieved before. However, a low level of adherence of parents or guardians is still evident.

Nevertheless, the author stressed that this activity has been taking place for several months now, and that she recommends that after the cases are treated at the clinic, they should be followed-up by home visits. Therefore, it is necessary to create a link with the School of Nursing of San Paulo, allowing the acute cases - and other cases - to be handled by the students in the form of a "home emergency service."

The creation and implementation of strategies to improve the quality of life of the Brazilian children - as the author of the article tells us - are challenges still being faced by health institutions today. In the sense of the need to establish connections with the different Nursing schools / courses in nursing education, research and continuing education is required.

\section{Presentación}

Fernando Ramos Porto ${ }^{1}$

El artículo titulado "La educación en el ambulatorio de pediatría", escrito por Maria del Carmo Marcondes Machado, analiza la problemática que existe en el cuidado de los niños en Brasil - específicamente en el Estado de San Paulo - y destaca los esfuerzos de las enfermeras (os) responsables de la Clínica Pediátrica del Hospital de las Clínicas dirigidos a mejorar las condiciones de salud para estos niños.

La autora destaca el bajo nivel económico en que vive la población producto de la pobreza y el bajo nivel espiritual incluyendo aspectos relacionados a la educación mental y moral. Incluso, en relación con el último nivel, la autora afirma que existe una correlación directa con el nivel económico, debido a la importancia atribuída al grado de instrucción de las mujeres que cuidan de sus hijos.

Por otra parte, Maria do Carmo Marcondes Machado ejemplifica, a través de situaciones vividas en el ambulatorio de Pediatría, extractos sobre la realidad de las condiciones socioeconómicas de la población. Destaca, además, que a pesar del bajo nivel económico, el compromiso y la dedicación de las madres para con sus hijos no es alcanzado, y los casos de atención deficiente a los niños se deben, principalmente, a la pobreza y al bajo nivel de instrucción.

Con el fin de ofrecer mejores condiciones para el cuidado de los niños, las enfermeras (os) de la Clínica Pediátrica criaron un grupo de madres llamado "Club de Madres". En este "grupo", las enfermeras (os) orientan a las mujeres a través instrucciones, ejercicios y películas con enfoque educativo; todo parte de una estrategia de aproximación para conseguir la vacunación de los niños, con resultados nunca antes obtenidos. Sin embargo, todavía es patente la baja adhesión de los padres y/o tutores.

Con todo, destacó, que dicha actividad está siendo llevada a cabo desde hace varios meses, y que lo más recomendable sería que después de que los casos fuesen tratados en la clínica, se les diese seguimiento con visitas domiciliares. Por lo tanto, es necesario la creación de un vinculo con la Escuela de Enfermería de San Paulo, porque de esta forma, los casos agudos - y otros tipos de casos - podrían ser atendidos por las (os) alumnas (os) en una especie de "servicio domiciliario de emergencia".

La creación e implementación de estrategias para mejorar la calidad de vida de los niños brasileños - como la autora del artículo nos relata - son desafíos a los que se enfrentan las instituciones de salud hasta nuestros días, es decir, en el sentido de la vinculación con las escuelas/cursos de enfermería en el ámbito de la enseñanza, investigación y extensión educativa. 


\title{
EDUCAĈ̃O EM AMBULATÓRIO DE PEDIATRIA *
}

\author{
MARIA Do CARMO MARCONDES MACHado **
}

Nossa impossibilidade de oferecer assistência direta à criança brasileira é quasi total. Por que? Que causas nos impedem de résolver o problema de nossa infancia desamparada?

Em primeiro lugar mencionaremos Baixo Nivel Econômico. Quasi toda a população vive na miséria. As causas e os remédios dessa miséria são problêmas de ordem econômica e política; não nos competem, ném cabsm numa palestra sobra assistência direta à criança. Mencionamos apenas o fato de năo podermos assistir a pessoas às quais falta o mínimo necessário à subsistência. A propósito entretanto, mencionarei alguns fatos: Uma das mães ouvindo que seria necessário dar frutas ao seu filho perguntou-me: O hospital as fornecerá? Não? Então näo interessam os seus ensinamentos. Outra a quem um dos medicos repreendeu severamente por dar alimentação inadequada ao seu filho respondeu: No inicio do mês fazemos tudo que o senhor manda, mas depois o dinheiro se acaba...

Baixo Nivel Espiritual compreendendo: Nivel de instruçăo quer geral ou especifica, isto é, conhecimentos de puericultura; Nivel mental, isto é, capacidade de observaçäo e te inieiativa da mảe; Ninel moral, isto é, o seu devotamento.

0 baixo nivel espiritual está ligado diretamente ao econô. mico, princinalmente no que concerne à instrução. As mães da nossa gente pobre, podem apresentar um desenvolvimento mental regular, podem ser devotadas, mas a falta de instrução elementar impede que compreendam a necessidade de assistência a seus filhos. Muitas vezes o desenvolvimento mental da mãe é prejudicado pela própria criação que teve, pois elas são na maioria dos casos sub-alimentadas desde a infância.

Desenvolvimento moral é o devotamento e o apego ao filho. Este, felizmente não parece estar tão diretamente ligado ao nivel econômico. Nossas mães proletárias são na maioria dos casos

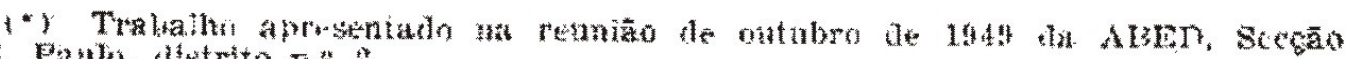
If* S. Paub, tistrito I.

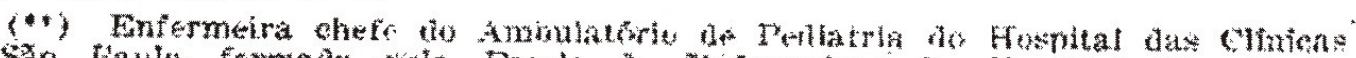

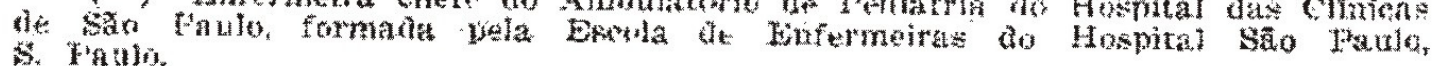


mais devotadas ao fithos que as nossas mães da elite social. $\mathrm{S}$ os filhos daquelas são mal assistidos mal cuidados, e devido ex clusivamente à miséria e à ignorância crassa.

Quanto à miséria uma enfermeira nada ou quase nada podi fazer. Quanto à ignorância combatềla é o nosso trabalho. a funçāo de toda enfermeira e especificamente das enfermeira: que trabalham em Saúde Pública ou em Ambulatórios.

O trabalho no ambulatório de Pediatria do Hospital das Cli. nicas é o seguinte: são dadas às mäes noçōes elementares de Higiene, rudimentos de puericultura, conselhos sobre a alimentação com demongtraçôes prâticas quanto à confecçāo de mamadeiras etc, à higiene alimentar, à higiene do ambiente. Há demongtra ção da técnica do banho de bêbê, conselhos sobre a vacinaçảo, indicaçäo de suas vantagens e importância, e sẫo divulgados pre. ceitos gerais sobre a educaçäo infantil.

Foi fundado um "Club de Mães" que se reune uma vez por mês à tarde, em hora diferente das consultas de ambulatório, para haver mais tempo e oportunidade destas participarem das demonstraçōes educativas. Há preleçōes e são passados filmes educativos e recreativos. Os filmes são obtidos no Consulado Americano e na Casa Isnard pelo Serviço Médico Social do Hospital das Chínicas. $O$ "Club" iniciou-se com doze mäes e aumentará conforme o interesse que a iniciativa suscitar. E oferecido um lanche às mães. Por falta absoluta de verba o Hospital nada fornece para a confecçäo do lanche. O Serviço enviou um oficio aos fornecedores de leite e päo deste Hospital e desde então êles fornecem cinco litros de leite e três quilos de biscoitos por mês. $O$ restante é feito com donativos angariados entre amigos.

$\mathrm{Na}$ fase anterior às preleçōes sobre a utilidade da vacinaçāo, essa atividade do ambulatório fracassou totalmente. De cada quatro mães trệs não retornavam para seus filhos completarem as doses da vacina. Assim $75 \%$ dos casos eram abandonados pelos próprios interessados que eram os pais ou responsáveis.

Quasi não pudemos ainda constatar o valor da parte educativa no ambulatório, pois ela existe somente há quatro meses, porem quanto à vacinação o abandono mesma caiu de $75 \%$ a $14 \%$, pois até hoje foram vacinadas oitenta e duas crianças; cada crianca toma quatro doses de vacina o que corresponde a trezentos e vinte e oito injeções. Só doze crianças abandonaram o trata. mento. interessante notar que das doze, seis näp maís compareceram ao ambulatório tambern.

Enfim, continuamos rosso trabalho cotidiano. As aulas säo dadas diariamente com demonstraçöes práticas. 
Trabalhamos em colaboraçăo uma enfermeira, alunas da Escola de Enfermagem de S. Paulo uma aluna da Escola de Serviço Social.

Näo ignoramos que melhor asistência daríamos se os casos de ambulatório fossem seguidos de vísitas domiciliares. Infelizmente este tipo de assistência nāo existe ainda no ambulatório de Pediatria do Hospital das Clínicas. Para assistir àquelas familias, às quais falta o mínimo de subsistência, os problemas seriam os já mencionados, numerosos e caros.

Temos porem planos de fazê-lo no futuro, contando com i auxilio da Escola de Enfermagem de S. Paulo, que nos darả maior número de alunas e permissāo para que as mesmas façam o "servico domiciliário de urgência", isto é, visitando apenas aqueles casos mais agudos, mais necessários.

Gostaria de näo deixar de mencionar, a dificuldade incrivel que vimos encontrando na execução de nossos planos; incompreensão de certos pais, indignaçāo de alguns devido à reaçāo das vacinas. Em uma das reuniões do "Club" convidámos trinta e duas mäes e naturalmente preparámos tudo inclusive lanche para todas elas. Compareceram apenas nove.

Como porem já tivemos sucesso no que concerne à imunologia, esperamos futuramente obter algum resultado nos outros campos de atividade deste ambulatório.

ESQUEMA DO TRABALHO JA REALIZADO NO AMBULATORIO

\begin{tabular}{|c|c|c|c|c|c|c|}
\hline MES & $\begin{array}{c}\text { Aulas da- } \\
\text { das p/ En- } \\
\text { fermelra }\end{array}$ & $\begin{array}{c}\text { Explic. } \\
\text { individ. }\end{array}$ & $\begin{array}{c}\text { Demonsh. } \\
\text { praticas }\end{array}$ & $\begin{array}{c}\text { Aulas dadas } \\
\text { p/ assiglentes } \\
\text { social }\end{array}$ & $\begin{array}{c}\text { Mäes } \\
\text { presentes }\end{array}$ & $\begin{array}{c}\text { Criancas } \\
\text { atenduds } \\
\text { ambulat. }\end{array}$ \\
\hline Juaho & 58 & - & 13 & 6 & 280 & 464 \\
\hline Julho & 86 & 122 & 26 & 17 & 287 & 474 \\
\hline Agosto & 15 & 217 & 89 & 17 & 406 & 656 \\
\hline Setembro & 8 & 211 & 26 & 10 & 814 & 657 \\
\hline
\end{tabular}

Nota: 0 número de aulas teóricas para grupos, dadas pela enfermeira, foram díminuidas em favor de maior número de aulas: individuais que são de muito maior proveito as mâes, principalmente às que são analfabutas. 